\title{
Self, Identity, and the Natural Environment: Exploring Implicit Connections With Nature ${ }^{1}$
}

\author{
P. Wesley Schultz ${ }^{2}$ and Jennifer Tabanico \\ California State University, San Marcos
}

\begin{abstract}
Using the Implicit Association Test (IAT), we examined the tendency for people to associate self with natural or built environments, the malleability of these scores across context, and the relationship between these implicit associations and explicit attitudes about environmental issues. Five studies are reported using a handheld IAT administration in a variety of field contexts. The psychometric properties of the handheld administration were comparable to those obtained with laboratory administration. The cumulative results across the 5 studies suggest that implicit selfnature associations are malleable, but that change requires long-term or repeated experiences. Findings are interpreted within a model of environmental identity.
\end{abstract}

This is the peer reviewed version of the following article: Schultz, P. W., \& Tabanico, J. (2007). Self, identity, and the natural environment. Journal of Applied Social Psychology, 37, 1219-1247. http://dx.doi.org/10.1111/j.1559-1816.2007.00210.x., which has been published in final form at Article Available (http://dx.doi.org/10.1111/j.1559- 1816.2007.00210.x). This article may be used for non-commercial purposes in accordance with Wiley Terms and Conditions for Self-Archiving.

${ }^{1}$ The authors thank Scott Gillis, Jessica Nolan, Carolyn Kitzman, Jackie Shabo, Christine Jarvis, Chris Shriver, Coral Bruni, Kelly Mueller, Katie Ports, Tania Rendon, and Sieto Beckers for their invaluable assistance on these studies. Funding for Studies 2, 3, and 4 was provided by a California State University Discretionary Lottery Grant from CSUSM. We also note the important contributions of Chrystal Adams and Ronald Tilos to Studies 3,4 , and 5. Portions of this paper were presented at the annual meeting of the Society for Personality and Social Psychology, Los Angeles, CA ( January 2003), and Austin, TX ( January 2004).

${ }^{2}$ Correspondence concerning this article should be addressed to Wesley Schultz, Department of Psychology, California State University, San Marcos, CA 92096. E-mail: wschultz@ csusm.edu 
One of the most fundamental beliefs that a person holds is about his or her relationship to the natural environment; that is, "Am I part of nature, or am I separate from nature?” The notion of an individual's connection with nature can be traced back through the writings of early philosophers, writers, naturalists, and scholars. Many authors have written about the human relationship with nature (e.g., Kahn, 1999), the importance of self and nature in understanding cultures throughout history (e.g., Elder \& Wong, 1994; Hoffman, 2000; Kline, 2000; Ponting, 1991), the importance of a sense of self in nature (e.g., Bateson, 1972; Kidner, 2001; Leopold, 1949; Searles, 1960; Thoreau, 1854/1987; Weigert, 1997), and the centrality of encounters with nature for our sense of self (Chawla, 1998; Nabhan \& Trimble, 1994) and well-being (Louv, 2005). Yet, despite the long history of these discussions, there has been little psychological research that incorporates aspects of the physical world into our sense of self, and almost all systematic studies of self and identity have focused on social processes (Baumeister, 1998; Baumeister \& Twenge, 2003).

Social psychologists have devoted a considerable amount of research to the study of self and identity (Baumeister, 1998; Brown, 1998; Higgins, 1996; Kunda, 2001; Markus, 1977). Social psychological research on self-concept has shown several clear findings: The self is organized as a hierarchical cognitive structure (i.e., schema); emerges from interaction in the world (not limited to the social world); is malleable across situations that activate rel- evant aspects of identity; and guides the formation of attitudes and behaviors (for a review of this work, see Baumeister, 1998). To date, research on self has been restricted primarily to social processes. Yet, as Clayton and Opotow (2003) pointed out, social psychological analyses of identity have ignored the larger, nonhuman context within which social interactions occur.

Several authors have begun to examine the relevance of self-nature connections to self and identity. Clayton and Opotow (2003) adopted the term environmental identity to refer to the inclusion of aspects of nature in a person's self-concept, but we prefer the more narrowly defined construct of self. Indeed, there is a lack of consensus among environmental writers about which term to use, and other authors have used 
ecological self or ecological identity (Neisser, 1997;

Thomashow, 1995). For the purposes of the present article, we will use the term environmental identity to refer to the molarlevel construct, and environmental self or self-concept to refer to the cognitive elements that comprise this identity.

Recent articles have attempted to operationalize these constructs. Clayton (2003) has worked to operationalize the construct of environmental identity, which she defines as "a sense of connection to some part of the non-human natural environment, based on history, emotional attachment, and/or similarity, that affects the ways in which we perceive and act toward the world" (pp. 45-46). In essence, environmental identity is the belief that the natural environment is an important part of who we are. Clayton argues that environmental identity is similar to other collective identities (e.g., gender, ethnic identity, national identity) in that it offers a sense of connection and belonging to a group. In three studies, she reported the development of a 24-item Environmental Identity Scale (EID). The findings showed that EID is related to values of self-transcendence (positively), horizontal collectivism (positively), vertical individualism (negatively), and reported environ- mental behavior (positively). In addition, the results showed EID to predict proenvironmental decisions in environmental conflict scenarios, and to correlate with a sense of moral obligation to protect animals and the environment.

A second line of work has focused on the cognitive dimension of environmental identity. Dutcher (2000) and Schultz (2001) have used a modified version of the Inclusion of Other in Self scale (IOS), which was developed by Aron and colleagues (Aron, Aron, \& Smollan, 1992; Aron, Aron, Tudor, \& Nelson, 1991), to measure the extent to which an individual includes nature within his or her cognitive representation of self. The modified scale consists of a series of seven overlapping circles labeled self and nature, and the item asks respondents to "Please circle the picture below that best describes your relationship with the natural environment. How interconnected are you with nature?” Results from survey data showed these responses to be positively correlated with self- 
reported environmental behavior, and to be correlated with other measures of general environmental attitudes.

While both of these approaches have yielded interesting and meaningful findings, both are based on the assumption that participants have an explicit belief about their relationships with the natural environment. Explicit measures of attitudes make three primary assumptions: The attitudes exist, they can be retrieved accurately from memory, and participants are willing to express them honestly (Oskamp \& Schultz, 2005). While the data suggest that participants do provide usable data in response to explicit questions, many respondents have expressed in our debriefing sessions that the topic is not one they had thought about before. An alternative approach, therefore, is to view these beliefs as primitive (Dunlap, Van Liere, Mertig, \& Jones, 2000).

Rokeach (1968) has described several types of primitive beliefs and has speculated about their implications for human belief systems. According to Rokeach, “a person's primitive beliefs represent his basic truths about physical reality, social reality, and the nature of the self; . . . they are so much taken for granted that they do not come up as a subject for discussion or controversy" (p. 6). Bem (1970) argued that these primitive beliefs are non- conscious. According to Bem,

Our most fundamental primitive beliefs are so taken for granted that we are apt not to notice that we hold them at all; we remain unaware of them until they are called to our attention or are brought into question by some bizarre circumstance in which they appear to be violated. . . . They are the nonconscious axioms upon which our other beliefs are built. (pp. 5-6)

We propose that an individual's belief about his or her relationship to the natural environment is one such zero-order primitive belief (for a similar argument, see Dunlap et al., 2000). These core beliefs serve as a reference point for the development of other more specific attitudes (Schultz, 2002; see also Kaiser, Hübner, \& Bogner, 2005; Stern, 2000). While an 
individual may not be consciously aware of this core belief, it nevertheless frames and guides the formation of other beliefs about nature, environmental programs and policies, and his or her concerns about environmental problems. We are not suggesting that the primitive belief will cause the emergence of a specific attitude or concern. Rather, the primitive belief will serve as a latent source for the development of specific concerns, but there are many other contextual and psychological factors than can alter the manifest attitude. To use a metaphor, the primitive belief is an aquifer for these more surface-level constructs. But (continuing the metaphor), the surface springs fed from an aquifer often can emerge in locations quite distant from the original source. Given our view that connectedness with nature is a zero-order belief, we believe that measuring it with explicit self-report questions might not be ideal. While sometimes they may reflect the underlying association (i.e., the spring is close to the aquifer), they also may miss the mark (i.e., the spring is some distance from the underlying source). That is, we question the validity of the explicit measure of connectedness. Fortunately, recent developments in social psychological research have provided a measurement tool with the potential for directly measuring primitive beliefs (Greenwald et al., 2002; Greenwald, McGhee, \& Schwartz, 1998; Greenwald, Nosek, \&Banaji, 2003).

In our prior work, we have made use of the Implicit Association Test (IAT) to measure the degree to which individuals hold cognitive associations between themselves and the natural environment (Schultz, Shriver, Tabanico, \& Khazian, 2004). The IAT procedure followed the customary sequence in which trials were presented in seven blocks. The categories used were NATURE/BUILT and ME/NOT-ME. The IAT effect was produced by subtracting the mean reaction time to the compatible trials (ME, NATURE; NOT-ME, BUILT) from the mean reaction time to the incompatible trials (ME, BUILT; NOT-ME, NATURE). The results from the two reported studies utilizing this IAT procedure showed several clear findings. First, there was a consistent IAT effect, wherein it was easier for participants to associate self with natural than 
with built stimuli. However, approximately $25 \%$ of the participants showed the opposite pattern, wherein it was easier to associate self with built stimuli. Second, the IAT effect showed a moderate level of test-retest reliability, even across a 4 -week period $(r=.49)$. Finally, the IAT effect correlated positively with scores on the Inclusion of Nature in Self (INS) scale, and also with two measures of general environmental attitudes.

The results from these two initial studies suggest that the IAT procedure may provide a useful tool for measuring implicit connections with nature. In addition, the results provide convergent validity for the construct of connectedness with nature. In the current paper, we present additional data on this IAT procedure, addressing limitations from previous research and testing new hypotheses about environmental self. In Study 1 , we report the development of a version of the IAT to run on a Palm ${ }^{\circledR}$ Pilot handheld device, and validate it with the desktop computer. In Study 2, we examine the influence of setting on the IAT scores by asking participants to complete the test in either a built (lobby/hallway), natural (park sitting area), or laboratory envi- ronment using the validated Palm ${ }^{\circledR}$ instrument. Finally, in Studies 3, 4, and 5 we examine experiences with natural and built environments that might change an individual's implicit connections with nature.

\section{Study 1: An IAT for the Palm ${ }^{\circledR}$}

The results from previous research have shown the usefulness of an implicit measure of environmental self (Schultz et al., 2004). However, the IAT procedure is based on reaction time and, therefore, has been limited to lab environments in which participants can use a desktop computer. Our goal in Study 1 is to develop an IAT procedure that can be administered outside of a laboratory room, in a field context. To move toward this goal, we developed an IAT procedure for the Palm ${ }^{\circledR}$ Pilot by modifying the original software developed by 
Dabbs, Bassett, and Dyomina (2003). ${ }^{3}$ The Palm ${ }^{\circledR}$ IAT followed the same seven-block sequence that has been used in prior IAT research. We began by validating the Palm ${ }^{\circledR}$ IAT with the computer IAT (Study 1). In Study 2, we randomly assigned participants to complete the IAT in three different environments. Finally, in Studies 3, 4, and 5, we used the Palm ${ }^{\circledR}$ measure in a variety of field settings.

\section{Method}

\section{Participants}

Participants in Study 1 were 56 undergraduate students (37 females, 19 males; $M$ age $=25.29$ years, $S D=9.15$ ) from California State University. Participants were recruited from the Psychology Department's Human Par- ticipant Pool. Our sample size was selected based on a power analysis of the expected large correlation between the Palm ${ }^{\circledR}$ and PC versions of the IAT.

\section{Materials}

A questionnaire was used to measure environmental attitudes and the demographic variables of age and gender. The questionnaire consisted of two environmental measures: the Environmental Motives scale (Schultz, 2001), and a revised version of Aron's Inclusion of Other in Self scale (Aron et al., 1992; see Schultz, 2001).

Environmental Motives scale (Schultz, 2000, 2001, 2002). The Environ- mental Motives scale provides a measure of an

\footnotetext{
${ }^{3}$ In our more recent work, we have developed a game-based interface for administering the IAT. The game interface can be administered in the field using a PocketPC, in the lab using a desktop PC, or on the World Wide Web (Bruni, Schultz, \& Bowlin, 2006). A demonstration version of the Internet game is available at www.conservationpsychology.org/game. The game interface simplifies administration, scoring, and interpretation. Researchers who are interested in using the game to measure implicit connections with nature should contact the first author.
} 
individual's concern about environmental problems because of the consequences that result from harming nature. Concern for environmental issues is divided into three categories: egoistic, altruistic, and biospheric. Participants rated 12 items on a 7point scale ranging from 1 (not important) to 7 (supreme importance). Egoistic items are me, my future, my prosperity, and my health; altruistic items are future generations, humanity, people in the community, and children; and biospheric items are plants, animals, marine life, and birds.

Inclusion of Nature in Self scale. This scale is an adaptation of Aron et al.'s (1992) Inclusion of Other in Self (IOS) scale. We refer to our modifi- cation as the Inclusion of Nature in Self (INS) scale.

Implicit Association Test (IAT). We used two versions of the IAT proce- dure. The first is identical to that used by Schultz et al. (2004) and was administered on a PC computer using Inquisit Version 1.32, distributed by Millisecond Software. We also used a version of the Palm ${ }^{\circledR}$ IAT developed by Singletap.com. ${ }^{4}$

Following the introduction, participants were presented with seven blocks of trials. There were four categories of words used: "Me," "Not Me," "Nature," and "Built.” The words used in each category are shown in Table 1 . The blocks were presented as follows: (a) Block 1: Nature—Built; (b) Block 2: Me-Not Me; (c) Block 3: Nature/Me-Built/Not Me; (d) Block 4: Nature/Me—Built/Not Me; (e) Block 5: Built— Nature; (f) Block 6: Built/ Me-Nature/Not Me; and (g) Block 7: Built/Me-Nature/Not Me.

In both the PC and Palm ${ }^{\circledR}$ versions, the words were presented in random- ized order within each of the seven blocks. We administered two versions of the Palm ${ }^{\circledR}$ and computer IAT in order to counterbalance for order of Nature/Me (Blocks 3 and 4) and Built/Me (Blocks 6 and 7). In the first rotation of the IAT, the compatible (Nature/Me) blocks

\footnotetext{
${ }^{4}$ The Palm ${ }^{\circledR}$ IAT version is freely available on the web site (www.singletap.com/research).
} 
were presented first; while in the second rotation, the incompatible (Built/Me) blocks were presented first. 


\section{Table 1}

Categories and Words Used to Measure Connectedness With Nature

Category

\begin{tabular}{|l|l|l|l|}
\hline NATURE & BUILT & ME & $\begin{array}{l}\text { NOT } \\
\text { ME }\end{array}$ \\
\hline Animals & Building & I & It \\
\hline Birds & Car & Me & Other \\
\hline Plants & City & Mine & Their \\
\hline Whales & Factory & Myself & Them \\
\hline Trees* & Street* & Self* & They* \\
\hline Water* & Computer* & My* & Theirs* \\
\hline
\end{tabular}

${ }^{*}$ Because the Palm ${ }^{\circledR}$ version of the IAT made use of six items, and the PC version used four items, the marked items were not used in the PC version of the IAT.

The Palm ${ }^{\circledR}$ version of the IAT varied slightly from the PC version in the number of stimuli used: The PC version used four word pairs, while the Palm ${ }^{\circledR}$ version used six word pairs. Subsequently, we added two additional pairs of items to the original PC stimuli list and used half of the stimuli pairs in the first block of compatible and incompatible trials (Items 1, 2, and 3 in Table 1), and half in the second block of compatible and incompatible trials (Items 4, 5, and 6 in Table 1).

\section{Procedure}

Upon arriving at the lab, participants provided their informed consent. They then were randomly assigned to receive one of two rotations of the IAT (compatible first or incompatible first). The IAT rotation that was administered on the computer matched the IAT version administered on the Palm ${ }^{\circledR}$. Next, participants were seated in front of the computer to complete the IAT.

Prior to beginning the test, the participant read through the 
instruction screens and was allowed to ask questions. After the participant completed the questionnaire, the researcher gave the participant a set of instructions for the Palm ${ }^{\circledR}$ IAT. Participants were asked if they had any questions and then were instructed to begin the test. After they completed the Palm ${ }^{\circledR}$ IAT, participants were debriefed.

\section{Results}

The desktop IAT data were processed using SPSS syntax. ${ }^{5}$ The Palm ${ }^{\circledR}$ IAT data were processed manually using Microsoft ${ }^{\circledR}$ Excel. Prior to comput- ing IAT scores, we screened response latencies for outliers. Following previous research (cf. Greenwald et al., 1998), latencies below 300 or above 3,000 were truncated. ${ }^{6}$

Data were screened for outliers on percentage correct. On the computer IAT, participants made an average of 3.10\% errors $(S D=3.76)$ on the compatible trials, and an average of $3.92 \%$ errors $(S D=3.85)$ on the incompatible trials. On the Palm ${ }^{\circledR}$ Pilot IAT, participants made an average of $2.38 \%$ errors $(S D=3.54)$ on the compatible trials, and an average of $4.54 \%$ errors $(S D=5.16)$ on the incompatible trials. For the compatible trials, error rates ranged from $0 \%$ to $16 \%$ (PC) and $0 \%$ to $12 \%$ (Palm ${ }^{\circledR}$ ); while for the incompatible trials, error rates ranged from $0 \%$ to $18 \%$ (PC) and $0 \%$ to $21 \%\left(\right.$ Palm $^{\circledR}$ ). We used a 30\% error rate cutoff, by which no participants were excluded from analysis.

To examine the internal consistency of the computer IAT and the Palm ${ }^{\circledR}$ IAT, we conducted three different tests for each instrument. For the computer IAT, we looked at the

\footnotetext{
${ }^{5}$ Information on SPSS syntax is available from the IAT Web site. Interested readers are directed to http://faculty.washington.edu/agg/iat_materials.htm 6 This is the traditional approach to scoring the IAT. The present study was completed before
}

Greenwald et al.'s (2003) new scoring algorithm was made available. While we use the traditional approach here (i.e., Study 1), in subsequent studies, we use the new scoring algorithm. 
relationship between the first $(M=795, S D=188)$ and second set $(M=673, S D=118)$ of compatible trials and found a positive, significant correlation $(r=.82, p<.001)$. The correlation between the first $(M=991, S D=238)$ and second set $(M=812, S D=189)$ of incom- patible trials also was significant $(r=.78, p<.001)$. Finally, we created IAT scores for the first and second set of compatible and incompatible trials, and found them to be correlated positively $(r=.63, p<$ $.001){ }^{7}$ We used a similar procedure for the Palm ${ }^{\circledR}$ data. We compared the first $(M=852, S D=220)$ and second compatible trials $(M=769, S D=164)$ and found a positive, significant correlation $(r=.80, p<.001)$. The correlation between the first $(M=1028, S D=223)$ and second set of incompatible trials $(M=937, S D=227)$ also was significant $(r=.74, p<.001)$. We then subtracted the first set of compatible words from the first set of incompatible words to create an IAT score and correlated those scores with the scores we obtained when we subtracted the second set of compatible words from the second set of incompatible words. The two IAT scores were positively correlated $(r=.25, p<.07)$.

To test our main hypothesis that there would be a positive, significant relationship between the computer IAT and the Palm ${ }^{\circledR}$ Pilot IAT, we focused on the combined IAT effect produced across the two blocks of compatible and incompatible trials (i.e., mean for all incompatible trials minus mean for all compatible trials). We found a positive, significant relationship between the computer IAT and the Palm ${ }^{\circledR}$ Pilot IAT ( $r=.49, p$ $<.001)$. The correlation is nearly identical to that reported previously by Schultz et al. (2004) for test-retest of the desktop IAT procedure $(r=.49)$.

Finally, we examined the relationship between Palm ${ }^{\circledR}$ IAT scores and our questionnaire measures (i.e., explicit) of connectedness with nature and environmental concern. The INS scale correlated .33 $(p<.05)$ with IAT scores. Scores for egoistic ( $\alpha=.90)$, altruistic $(\alpha=.89)$, and biospheric environmental concerns $(\alpha=.86)$ were created by averaging the relevant items from the Environmental Motives scale. Correlations show that IAT scores were positively correlated

${ }^{7}$ This is comparable to a split-half reliability coefficient. 
with biospheric concerns $(r=.31, p<.05)$ and altruistic concerns $(r=.25, p=.07)$, but not with egoistic concerns ( $r=$ $.02, n s)$.

\section{Study 2: Malleability of Implicit Associations}

Following the validation of the Palm ${ }^{\circledR}$ IAT procedure, we conducted an experimental study outside the laboratory to examine the influence of context on IAT scores. If the IATnature procedure is measuring a primitive belief, we would not expect it to be malleable by the context in which it was assessed; yet, we would expect that it would be malleable with repeated exposure to natural or built environments. Furthermore, in order to move from the lab to field, it is important to examine the influence of context on IAT scores. To date, all of our data had been collected in a controlled laboratory environment, so measuring the IAT in a field context is an important first step to moving beyond the lab.

\section{Method}

\section{Participants}

Data were obtained from 60 undergraduate students (27 males, 33 females; $\mathrm{M}$ age $=20.85$ years, $\mathrm{SD}=3.39$ ) at California State University. Par- ticipants were recruited from the Psychology Department's Human Participant Pool. A sample size of 60 was selected in order to allow for 20 participants in each of three testing locations, providing $80 \%$ power to detect a large effect. 


\section{Materials}

Materials were identical to those used in Study 1. A questionnaire was used to gather demographics and to measure environmental attitudes. The questionnaire contains two measures of environmental attitudes: Schultz's Environmental Motives scale (2001), and the INS scale. The Palm ${ }^{\circledR}$ Pilot version of the IAT that we used in Study 1 was used again in Study 2 to measure implicit connections with natural and built environments.

\section{Procedure}

After providing their informed consent, participants were randomly assigned to one of three locations (an outdoor public seating area in agrassed and vegetated courtyard, a lab room, or an indoor public seating area inside a university building). Participants also were randomly assigned to an IAT rotation (compatible first or incompatible first) and order (IAT first or questionnaire first).

Participants were asked to sit in their assigned settings for 5 min without talking or doing any other activity. Participants were told that they would be asked at a later time to remember as much as possible about their environment. This was done to ensure that participants were actively aware of their surroundings.

After the 5-min period, participants completed the questionnaire and the Palm ${ }^{\circledR}$ version of the IAT (in randomized order). Upon completing the tasks, participants returned to the lab and were asked to write down as many things as they could remember about the environment in which they had been sitting. Participants then were debriefed. 


\section{Results}

Cronbach's alpha was used to evaluate reliability for all of the questionnaire measures. All scales showed an acceptable level of reliability: biospheric environmental concerns, $\alpha=.88$; altruistic environmental concerns, $\alpha=.82$; and egoistic environmental concerns, $\alpha=.92$.

On the Palm ${ }^{\circledR}$ Pilot-administered IAT, participants made an average of $4.03 \%$ errors $(S D=5.10)$ on the compatible trials, and an average of $4.66 \%$ errors $(S D=7.56)$ on the incompatible trials. Data were screened for high error rates. We used a 30\% cutoff rule for error rates: 1 participant had a $46 \%$ error rate on the incompatible trials and was excluded from the analysis of IAT data.

Scores for the IAT were produced using the improved scoring algorithm provided by Greenwald et al. (2003). The improved scoring procedure makes use of all compatible and incompatible trials, and divides the mean reaction- time difference between compatible and incompatible trials by the standard deviation to produce a $D$ score. Because the Palm ${ }^{\circledR}$ IAT does not have a built-in feedback mechanism (i.e., correct responses are processed in the same way as incorrect responses), we applied a 300-ms penalty for incorrect responses. The mean IAT-D score across the 59 participants was $.40(S D=.33)$. Internal reliability, calculated by correlating the two IAT subscales (i.e., Block 6 - Block 3, with Block 7 - Block 4), was $.40(p<.01)$.

Our primary hypothesis about the effect of context on IAT scores was tested with a one-way ANOVA. As expected, this analysis reveals no significant differences across the three conditions on any of the scale scores: explicit or implicit. The test of significance for the IAT-D scores was as follows: $F(2$, 56) $=0.26, p=.77$.

Further analyses examined other aspects of the responses. While the mean scores did not differ, there was a general tendency for participants to make slower responses overall when in a public setting (both built and natural) than when in the laboratory. That is, overall response latencies were larger in the field than in the lab. However, because the IAT effect is relative - that is, produced by subtracting the latencies for 
compatible and incompatible trials-this response pattern did not affect substantially the overall IAT score (for a discussion of the relationship between overall response latency and IAT effects, see Greenwald, Nosek, \& Banaji, 2003; Cai, Sriram, Greenwald, \& McFarland, 2004).

Additional analyses were conducted to examine the impact of setting on explicit measures of environmental concern. Scores on the biospheric envi- ronmental concerns scale and the INS scale were analyzed using one-way ANOVAs with location (3 levels: lab, vegetated courtyard, or indoor waiting space) as the independent variable. The results from these analyses show no significant differences between groups, although in every case, the means were in the same direction, with the vegetated courtyard yielding the highest scores.

Our final set of analyses examined the relationship between the explicit measures and the implicit Palm ${ }^{\circledR}$ measure. As predicted, there was a positive relationship between both the INS scale $(M=3.31, S D=1.19)$ and Palm ${ }^{\circledR}$ IAT-D scores $(r=$ $.25, p=.05)$. The results for the environmental motives items were in the expected direction, but did not reach statistical significance.

\section{Study 3: A Day at the Park}

The results from the first two studies provide evidence for the reliability and validity of an IAT measure of implicit connections with nature. The results also indicate that the IAT procedure, which utilizes response latencies, can be administered in a field setting. Study 2's results show that context does not influence IAT scores: Being in a natural environment for 5 minutes is not sufficient to alter implicit connections with nature. Combined with the test- retest data reported by Schultz et al. (2004), this suggests that implicit con- nections with nature are relatively stable across time and situation. But are these associations malleable? Can they change as the result of an experience?

In Study 3, we examine implicit connections with nature among a sample of visitors at the San Diego Wild Animal Park. The Park's stated mission is to "connect people to animals and conservation.” Park exhibits and experi- ences are designed to promote a sense of connection with the plants and animals 
within the site. Most of the animals are free-roaming in natural environments, and attempts are made to provide guests with "immersion" experiences wherein they have a direct encounter with an animal. Our research question is: Will spending a day at the Wild Animal Park change a person's implicit connections with nature?

\section{Method}

\section{Participants}

Data were collected from 131 visitors ( 74 males, 57 females) at the San Diego Wild Animal Park. Independent samples of guests were obtained from the entry location $(N=75)$ and the exit $(N=56)$.

\section{Materials}

A six-item questionnaire was developed to measure demographic variables, past experience with the park, and the approximate number of hours spent in the park. The questionnaire also included an explicit measure of environmental concern: "How concerned are you personally about environ- mental problems?” Responses on the environmental attitude measure were rated on a 4-point scale ranging from 1 (not at all) to 4 (a great deal). This question has been widely used in public opinion polls as a broad measure of environmental concern (Dunlap, Gallup, \& Gallup, 1995; Dunlap \& Saad, 2001). 
Implicit environmental associations were measured using the IAT proce- dure administered on a Palm ${ }^{\circledR}$ Pilot (see www.singletap.com/research). The Palm ${ }^{\circledR}$ IAT procedure was identical to that used in the previous two studies, but with a new set of stimuli. In a series of separate studies, we have tested different words to represent the categories of Nature and Built. The results from our pilot testing suggest that the words selected generally do not influence the IAT scores; it is the categories that matter. In fact, we found that the IAT effect is equally strong for both positively and negatively valenced Nature and Built words.

In the current study, we used two sets of stimuli. A generic version of the IAT was administered using stimuli matched on valence, number of letters, and frequency of occurrence in the English language. ${ }^{8}$ The Built words were ship, palace, and museum; while the Nature words were rock, nectar, and animal. The second version of the IAT was tailored more specifically for the Wild Animal Park (zebra, elephant, animals), again using Built words matched on valence, word length, and frequency (chair, hospital, cabinet).

${ }^{8}$ Pilot data were based on responses from 33 undergraduate students. A stimuli list contain- ing 100 Built and Nature words was generated, and students rated the valence of each word on a 9-point scale ranging from 1 (extremely negative) to9 (extremely positive). Words with a mean valence rating of 5.4 or less were considered negative; and words with a mean valence rating of 5.5 or greater were considered positive. Valence ratings from this pilot study correlated at .91 with valence ratings from Bradley and Lang's (1999) affective norms for English words. We selected three BuiltNature pairs from the larger word lists. Built-Nature word pairs for this study were matched exactly for number of syllables and number of letters, and were within .40 on word valence and .40 on written frequency. We obtained the Kucera-Francis written frequency for each word using the MRC Psycholinguistic Database: Machine Usable Dictionary (Version 2.00). Written frequencies for words included in the Kucera-Francis list range from 1 to 700 . 


\section{Procedure}

Random samples of participants were obtained by selecting every third visitor at each turnstile. Each participant was greeted and asked to provide informed consent in order to be part of the study. After providing their informed consent, participants were interviewed briefly, familiarized with the Palm ${ }^{\circledR}$ procedure, and randomly assigned to complete either the Wild Animal Park (WAP) or the generic version of the IAT. Each participant was provided with detailed individualized instruction and a demonstration on how to use and complete the Palm ${ }^{\circledR}$ IAT test. After they completed the IAT, participants were debriefed.

\section{Results}

Data were obtained from 131 participants: 75 at the entrance and 56 at the exit. Of the sample, 64 completed the generic version and 67 completed the version specific to the WAP. Of the 131 participants, 58 were annual pass holders and 73 were not. Of the visitors who had been to the Park in the past year, the mean number of visits was 2.37. Of the 56 visitors who were exiting the Park, the mean length of stay was 4.07 hr.

Palm ${ }^{\circledR}$ IAT data were processed using a data-converting macro developed for Microsoft ${ }^{\circledR}$ Excel. Data were extracted, and the mean reaction time and error rate were computed for each of the seven blocks of trials. Following Greenwald et al. (2003), our primary measure of implicit association was the D score. Because the Palm ${ }^{\circledR}$ IAT does not have a built-in feedback mechanism to indicate correct or incorrect answers, we applied a 300-ms penalty for incorrect responses.

Prior to conducting our analyses, the IAT data were screened for error rates. In this sample, the mean error rate for the two compatible trials was $5 \%$ and $4 \%$, while the mean error rate for the incompatible trails was $6 \%$ and $8 \%$. Any participant who had an error rate of more than $30 \%$ on any of the four 
critical blocks of trials (incompatible or compatible) was excluded from the analysis. Based on this screening requirement, 7 participants were excluded, leaving a working sample of 124. Among the final sample, the mean D score was .45 , with a range from -0.44 to 1.13 . Internal reliability for the IAT, calculated by correlating the two subscales, was .58.

To directly test the effect of the Park experience on environmental associations, IAT scores were analyzed using a 2 (Version: generic or specific) X 2 (Arrival: entry or exit) factorial ANOVA. The results reveal a significant main effect for arrival, $F(1,120)=5.39, p<.05$, partial $\eta^{2}=.04$. Neither the version effect nor the Arrival X Version interaction was significant. Mean scores show that participants who were arriving at the park scored significantly lower $(M=0.38, S D=$ $0.40)$ than did participants who were exiting the park $(M=0.54$, $S D=0.34)$. Mean scores, which are shown separately for the two versions, are presented in Figure 1.

A similar analysis was performed using the explicit measure of environ- mental concern. Mean scores show no significant difference from entry to exit.

Finally, the IAT data were examined for possible gender effects. A $t$ test for independent means shows women $(M=$ $0.55, S D=0.33$ ) to have higher implicit connections with nature than men $(M=0.37, S D=0.40), t(122)=2.73, p \square .01$. There were no significant differences on explicit concern about environmental issues, $t(122)=0.67, p=.50$. 



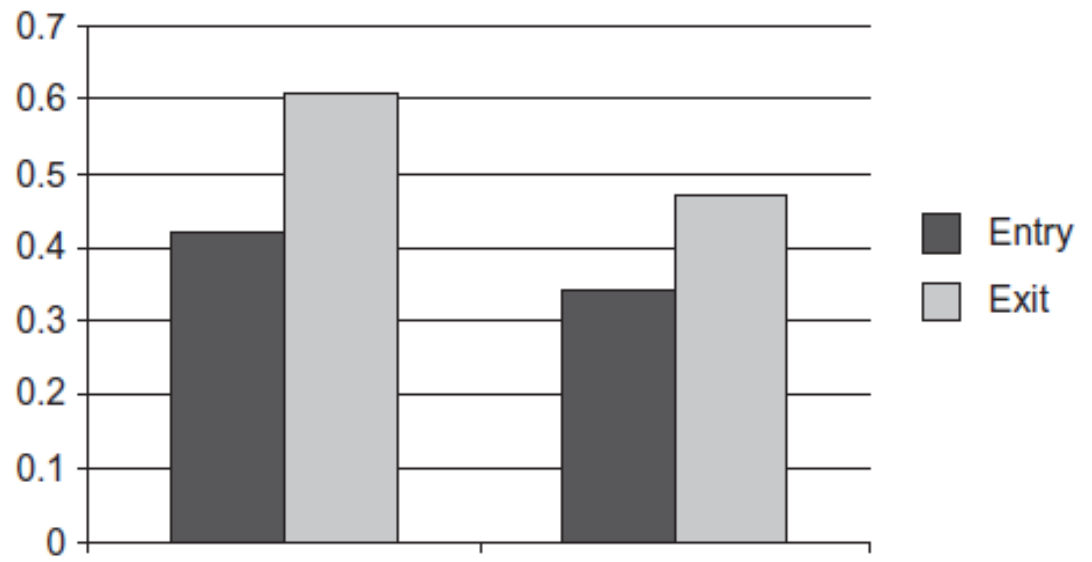

Specific (WAP)

Generic

\section{IAT Version}

Figure 1. Mean Implicit Association Test D scores for two versions before and after a day at the park.

\section{Study 4: Tracking Visitors at the Park}

The results from Study 3 show that guests exiting the WAP had significantly higher IAT-Nature scores than did guests entering the Park. However, these were independent samples and the data do not lend themselves to analyses of change within each person. To further examine this issue, we conducted a follow-up study using a within-subjects design.

\section{Method}

\section{Participants}

Participants in the study were 40 visitors (27 females, 12 males, 1 un- reported gender) to the San Diego Wild Animal Park on two consecutive days. A sample size of 40 was selected based on a power analysis, assuming a medium effect approximately equal to that obtained in Study 3 for the generic test, and with a desired power of at least .80 for a dependent- 
means $t$ test. Participants were recruited as they entered the Park, and only visitors who were not annual pass holders were included in this sample. As an incentive, participants were given a \$5 gift certificate to use during their day at the Park and two return tickets to the Park upon completion of the study.

\section{Materials}

A two-part questionnaire was developed to measure demographic variables, past experiences with the Park, approximate number of hours spent in the park, and experiences while at the Park. The questionnaire also included two explicit measures of environmental concern. The first measure asked "How concerned are you personally about environmental problems?” (Dunlap \& Saad, 2001). The second measure was the INS scale (Schultz, 2001) in which participants were shown a set of seven circles with various degrees of overlap and were asked to "Please circle the picture below which best describes your relationship with the natural environment.” Responses were rated on a 7-point scale ranging from 1 (circles have no overlap) to 7 (circles overlap entirely), with varying degrees of overlap in between.

The questionnaire also contained eight items designed to measure affective mood state. Participants were asked to rate their current moods on the following items: happy, sad, relaxed, tense, energetic, sluggish, irritated, and carefree. These items were adapted from Ajzen and Driver (2001).

Implicit environmental associations were measured using the Palm ${ }^{\circledR}$ IAT. The IAT procedure was identical to the generic version reported in Study 3. There were seven blocks of trials, and the four categories were Nature, Built, Me, and Not Me. The items are presented in Table 1.

\section{Procedure}

Visitors to the Park were approached between the hours of 9 a.m. and 11a.m. as they entered. After they had agreed to 
participate, participants were interviewed briefly. Participants then were familiarized with the Palm ${ }^{\circledR}$ Pilot. Each participant was provided with detailed instructions on how to use and complete the Palm ${ }^{\circledR}$ Pilot IAT test, and the interviewer then demonstrated the procedure. Following the demonstration, participants completed the IAT test.

Participants then were asked to take the Palm ${ }^{\circledR}$ Pilot with them during their day at the Park and to complete the IAT measure when the device's alarm sounded. The Palm ${ }^{\circledR}$ Pilot was programmed to alarm three times during the day: 12 noon, 1 p.m., and 2 p.m. The alarm was demonstrated to familiarize participants with the sound. Participants were given a map and a pen and were asked to mark their routes through the Park and to indicate the places where they completed the Palm ${ }^{\circledR}$ Pilot IAT tests. Participants were instructed to return to the testing booth at a specific time (3 p.m.), at which time they were interviewed again, and they completed the Palm ${ }^{\circledR}$ Pilot IAT test. After participants completed the final Palm ${ }^{\circledR}$ Pilot IAT test, they were debriefed and thanked.

\section{Results}

Of the 40 participants who agreed to participate in the study, Palm ${ }^{\circledR}$ Pilots were returned by 37 , and 3 Palm ${ }^{\circledR}$ Pilots were found abandoned in the Park. Of the 37 devices that were returned, complete interview and final IAT data were obtained from 32. There were 5 participants who refused to complete the IAT procedure a final time at the testing booth. Of the 37 who returned for the final interview, all but 1 reported completing the IAT personally during their day at the Park.

Our first set of analyses tested for changes in explicit environmental attitudes. The first item ("How concerned are you personally about environ- mental problems?”) was tested using a paired-sample $t$ test. The results showed that the change from entry $(M=3.33, S D=0.79 ; N=36)$ to exit $(M=3.42$, $S D=0.77 ; N=36$ ) was not statistically significant, $t(35)=$ 
1.36, $p=.18(r=.89)$. For the INS scale (circles), the change from entry $(M=4.92, S D=1.32)$ to exit $(M=5.14, S D=$ 1.33) was statistically significant, $t(35)=2.26, p=.03(r=$ $.90)$.

Our second set of analyses examines changes in affective mood state across the stay. Based on results from Study 3, we aggregated the mood items to produce a single measure of positive mood. Results showed no significant change in affective state as a result of spending time at the Park, $t(35)=$ $0.69, p=.49(r=.48)$.

Our third set of analyses examines changes in implicit connection with nature, as measured with the Palm ${ }^{\mathbb{R}}$ IAT. Given the gender differences found for the IAT measure in Study 3, we conducted a 2 (Time: entry vs. exit) X 2 (Gender) mixed-model ANOVA. The results revealed a significant main effect for gender, $F(1,28)=10.79, p=.003$; and a marginally significant main effect for time, $F(1,28)=3.65, p=.06$. The two-way interaction was not significant, $F(1,28)=1.11, p=$ .30. Mean scores show that women $(M=0.51)$ scored higher than did men $(M=0.23)$, and that the effect size was large (partial $\eta^{2}=.28$ ). Mean scores also show that participants had higher IAT scores when exiting $(M=0.42)$ the Park than when entering $(M=0.23)$, and the effect size was medium (partial $\eta^{2}=.12$ ).

In our next set of analyses, we examine change across time in the IAT scores in more detail. The data reported in the preceding paragraph were obtained at the testing booth, but there were three additional testing opportunities throughout the day. Although participants were instructed to complete the IAT five times during the day, not all participants did so. As a result, there is a differential pattern of missing cases across the five time periods, and complete IAT data at all times were obtained from only 17 participants. Consequently, we chose to report the data descriptively, with mean scores at each time period. The scores show a curvilinear pattern, increasing from entry ( $M$ $=0.35, S D=0.45 ; N=37)$, through Time $3(M=0.53, S D$ $=0.41 ; N=28)$, and then decreasing at Time $4(M=0.40, S D$ $=0.32 ; N=28)$ and Time $5(M=0.44, S D=0.35 ; N=32)$, although still higher than baseline.

Finally, we examined the stability of IAT scores across the five measurement points during the day. Correlation 
coefficients among the five scores ranged from .11 to .72, with a mean across the 10 correlations of .38. A factor analysis of the five scores further confirms the underlying communality of the items. A principal axis extraction procedure yields a single factor, which explained $48 \%$ of the variance.

\section{Study 5: Spending Time in Nature}

The studies reported thus far provide evidence for the usefulness of self- nature associations in understanding environmental attitudes. Study 4 showed that guests leaving the San Diego Wild Animal Park had higher implicit connection with nature than did guests entering the Park. However, absence of a control group qualifies any clear conclusions about causation, and there are a number of possible alternative explanations for the observed differences. Our explanation is that spending time at the Park increased the extent to which the individual associated self with nature. But perhaps the context is irrelevant, and spending time in any recreational activity would produce the same effect. Also, what is it about the WAP that produced these changes? Would spending time in any natural environment be associated with an increase in associations with nature?

To address these questions, we conducted a fifth study examining implicit associations with nature among visitors to six different locations: three natural, and three built. In addition, we sought to include built environments that would attract environmentally oriented individuals (an indoor rockclimbing facility), as well as natural environments that would attract less environmentally oriented individuals (a golf course). Further, we included a measure of affective state in order to test the relationship between mood and implicit connections with nature. 
Data were collected from 372 visitors (216 males, 149 females, 7 gender not specified) at six different locations: exercise gym, indoor rock-climbing facility, library, beach, golf course, and state hiking trail. The locations were selected to provide three natural environments and three built environments, and to reflect a wide range of interests. With the exception of the library, the locations were recreational.

Following the procedure used in the previous study at the WAP, independent samples of participants arriving $(N=182)$ and departing $(N=190)$ each location were interviewed. Our target sample size was 60 from each location (30 entry and 30 exit), but there were some small variations in sample size across the locations (gym, $n=75$; rock climbing, $n=53$; golf course, $n=61$; library, $n=61$; beach, $n=58$; and hiking trail, $n=64)$.

\section{Materials}

A 12-item questionnaire was developed to measure demographic variables, past experiences with the location, approximate number of hours spent in the location, and current affective state. The questionnaire also included a measure of explicit environmental concern: "How concerned are you person- ally about environmental problems?” Affective mood state was measured by asking participants to indicate the extent to which they were currently feeling happy, sad, relaxed, tense, energetic, sluggish, irritated, and carefree. Each item was rated on a 7-point Likert scale. The items were adapted from Ajzen and Driver (2001).

Implicit environmental associations were obtained using the IAT procedure (see www.singletap.com/research) administered on a Palm ${ }^{\circledR}$ Pilot. The procedure was identical to the generic version used at the WAP (described in Study 3).

\section{Procedure}

Because of the relatively low volume of visitors at these locations, sampling consisted of every individual who 
entered or exited the location during our testing hours. Each person was greeted and asked to provide informed consent in order to be part of the study. After providing their informed consent, participants were interviewed briefly. Next, participants were introduced to the Palm ${ }^{\circledR}$ Pilot. Each participant was provided with detailed instructions and a demonstration on how to use and complete the Palm ${ }^{\circledR}$ Pilot IAT. The instructions and demonstration were identical to that used in Study 3. After they completed the IAT, participants were debriefed. 


\section{Results}

The Palm ${ }^{\circledR}$ Pilot IAT data were processed using the dataconverter Microsoft ${ }^{\circledR}$ Excel macro. Data were extracted, and the mean reaction time and error rate were computed for each of the seven blocks of trials. Following Greenwald et al. (2003), our primary measure of implicit association was the $\mathrm{D}$ score. Because the Palm ${ }^{\circledR}$ IAT does not have a built-in feedback mecha- nism to indicate correct and incorrect answers, we applied a 300-ms penalty for incorrect responses.

Prior to conducting our analyses, the IAT data were screened for error rates. Any participant who made more than 30\% errors on any of the four critical blocks of trials (incompatible or compatible) was excluded from the analysis. The final working sample was 334. In this sample, the mean error rates for the two compatible trials were $4.31 \%$ and $3.95 \%$, respectively; and the mean error rates for the incompatible trials were $6.24 \%$ and $4.69 \%$, respectively. The mean D score was .55 (range $=-0.91$ to 1.44$)$. Across the full sample, the internal reliability of the IAT was .46 $(p<.001)$.

Our first set of analyses examined the characteristics of the people who utilized each of the locations. Analyses of gender showed a significant differ- ence in the number of men and women interviewed at each location, $\chi^{2}(5, N=372)=41.27, p$ $<.001$, Cramer's $V=.36$. More men than women were interviewed at the gym (62\%), indoor rock-climbing facility (53\%), and golf course (96\%); whereas more women than men were interviewed at the library (53\%), beach (53\%), and hiking trail (56\%). Importantly, the percentage of men and women interviewed entering and exiting the locations did notdiffer, $\chi^{2}$ $(1, N=372)=0.04, n s$; and women and men did not differ in the amount of time they spent in each of the locations. As was found in the previous studies, women scored significantly higher on the IAT measure $(M=0.64, S D=0.29)$ than did men $(M=0.48, S D=0.39), t(326)=4.07, p<.01$; and women tended to make fewer errors on the IAT trials than did men. There were no gender differences in the explicit environmental concern measure.

Additional analyses were performed on the amount of time 
participants exiting the locations reported being there, as well as the reported number of times participants had been to the location. Results showed a significant difference across location to the question "In the past year, approximately how many times have you been to [this location]?”: $F(5,328)=$ 32.16, $p<.001$. Follow-up Tukey's post hoc comparisons show that the exercise gym ( $M=163$ times) was the highest, followed by the library $(M=97)$. The beach $(M=40)$, golf course $(M=51)$, and indoor rock-climbing facility $(M=35)$ were relatively similar, and the hiking trail was visited least frequently $(M=15)$. With regard to amount of time spent in each location on the day they were interviewed, there were significant differences across the locations, $F(5,165)=29.29$, $p<.001$. Post hoc Tukey's honestly significant difference (HSD) comparisons reveal that participants stayed at the golf course $(M=212 \mathrm{~min}$ ) significantly longer than at the beach ( $M$ = $81 \mathrm{~min})$, indoor rock-climbing facility ( $M=75 \mathrm{~min})$, library $(M=71 \mathrm{~min}), \operatorname{gym}(M=63 \mathrm{~min})$, and hiking trail $(M=59$ $\min )$.

Our main analysis was a 6 (Location) $¥ 2$ (Arrival: entry vs. exit) ANOVA with the IAT-D score as the dependent measure. However, results from this analysis showed no main effects or interactions. As planned, we collapsed the office, indoor rock climbing, and gym into a "built" category; and the hiking trail, golf course, and beach into a "nature" condition. We proceeded to conduct a 2 (Condition: natural, built) X 2 (Arrival: entry, exit) ANOVA with the IAT-D score as the dependent variable. The results show no significant differences across conditions.

Given the wide range of time spent in each of the locations, we conducted additional correlational analyses. For participants who were departing, we correlated the amount of time they reported spending at the location with the IAT-D score. For the gym (.12), rock climbing (-.05), library (.04), and golf course (.29), these correlations were not significant. However, for the beach $(r=.38, p=.05)$ and hiking trail $(r=.49, p<.01)$, the relationship was posi- tive and significant. For participants who were arriving, we correlated the number of times they reported visiting the location with IAT-D scores. The results show one significant correlation: Participants who reported coming to the hiking trail more often had higher IAT-D scores $(r=.27, p$ $.05, N=55)$. No other correlations were significant. 
The eight mood items were factor-analyzed using principal components extraction. The analysis reveals one factor that explained $38 \%$ of the variance. Communalities for the items ranged from .27 (energetic) to .51 (happy). The single factor reflected a positive-negative mood continuum, with happy (.71), relaxed (.60), energetic (.51), and carefree (.59) loading positively; and sad (-.65), tense (-.63), sluggish (-.55), and irritated (-.67) loading negatively.

A mood score was created by reversing the negative items and averaging the eight items $(a=.76)$. A 6 (Location) $¥ 2$ (Arrival: entry, exit) analysis reveals a significant main effect for location, $F(5,321)=9.82, p<.001$. A Tukey's HSD for the main effect reveals two clear subsets. Participants were in a better mood at the first subset, which was the beach $(M=5.86)$, golf course $(M=5.86)$, and hiking trail $(M=5.82)$, than at the second subset, which consists of the library $(M=5.14)$, indoor rock-climbing facility $(M=5.28)$, or exercise gym $(M$ $=5.58)$.

Finally, we wanted to examine the mediated link between time in each location and mood. Analyses of the IAT-D scores reveal that the amount of time spent at the hiking trail and at the beach was positively correlated with IAT-D scores. However, scores on the mood measure were not correlated with IAT-D scores ( $r=.06, n s, N=333$ ). Given this lack of effect, tests of mediation are unwarranted; that is, there is no evidence that the relationship between time spent in nature (at the beach or hiking trial) and connection to nature is mediated by mood.

\section{General Discussion}

The results from the five studies reported suggest that the IAT can provide a useful tool for measuring and testing hypotheses about an individual's connection to nature. Using the Implicit Association Test, we found a number of theoretically meaningful and predicted results. In Studies 1 and 2, we reported the development and validation of an IAT procedure designed to run on a Palm ${ }^{\circledR}$ Pilot. In Studies 3 and 4, we found evidence for an increase in connectedness with nature after spending the day at the Wild Animal Park. Study 5 found additional evidence that spending time in a natural environment 
(a hiking trail and the beach, but not a golf course) was associated with an increase in connectedness with nature.

Across the studies, we found considerable evidence for the reliability of the IAT-nature measure. Previous research with the IAT has found modest levels of test-retest reliability (Cunningham, Preacher, \& Banaji, 2001). Our results are consistent with these findings, as evidenced in the split-half correlations generated by correlating scores on the IAT for the first and second blocks of compatible and incompatible trials. Across the five studies, we found internal reliability scores of $.25, .40, .58, .38$, and .46 , respectively. Similarly, the results from Study 1 show a comparable level of reliability between assessments on the Palm ${ }^{\circledR}$ and the PC, and Study 2 shows that IAT scores were not affected by the context in which they were measured (nor were explicit measures).

Consistently across the five studies, participants showed a positive IAT effect. This indicates that participants had stronger associations between self and nature, than between self and built stimuli. While the overall IAT scores must be interpreted with caution (Blanton \& Jaccard, 2006), the relative difference between associations with natural and built environments is mean- ingful, and the consistently positive IAT-D score across the five reported studies warrants comment.

An intriguing possibility is a biological predisposition for a positive association with nature. This interpretation would be consistent with the biophilia hypothesis (cf. Kellert, 1996; Wilson, 1984; for a review of the arguments for and against biophilia, see Kahn, 1999). As Wilson $(1984,1993)$ outlined it, biophilia is a genetic tendency to affiliate with life. According to Wilson (1993), it is "the innately emotional affiliation of human beings to other living organisms" (p. 31). This biological predisposition exists at an unconscious level in all people, and manifests itself in our thoughts, feelings, behaviors, and culture.

Although we are sympathetic toward the biophilia explanation for our findings, there are some inconsistencies and alternative explanations. First, not everyone shows this tendency. Indeed, approximately $25 \%$ of our samples had negative IAT scores, indicating a stronger association 
between self and built environments. In debriefing sessions, a number of participants expressed their preference for built environments, and reported that it was easier to associate self with built stimuli (e.g., car). Second, IAT scores were shown to change as a result of experience. If the IAT effect resulted from a biological disposition, then we would not expect it to change so easily. So, while we believe that there is a basic biological disposition to associate self with natural environments, repeated experiences may override this tendency (for a similar argument about biophobia and the evolutionary basis of fear, see Öhman et al., 1979, and Öhman \& Mineka, 2001). In future research, we hope to provide additional data on the experiences and psychological variables that are associated with these differences.

While we have argued that connectedness with nature is a primitive belief, our data suggest that it might be changeable by experience. Though the lack of experimental design in Studies 3,4 , and 5 tempers any conclusions about causation, we believe that some speculation is warranted. Our results suggest that implicit associations with nature are not changed easily as a consequence of context (as evidenced by Study 2 in which no differences were found after $5 \mathrm{~min}$ ); yet they do appear to be malleable after several hours in a natural environment, as evidenced by the Wild Animal Park results (particularly the WAP tracking data reported in Study 4). This conclusion is supported further by significant correlations between frequency of visits to natural places and IAT scores that were found in Study 5.

But if implicit connections with nature do change, what is the mechanism? Is it an activation effect, wherein the connections already exist and are made salient by contextual factors? Or is it the accretion of experiences that leads to greater cognitive associations, as some data might suggest (Karpinski \& Hilton, 2001)? An activation explanation would lead to less durable changes, whereas an accretion explanation would produce longer lasting associations with nature. These questions remain for future research.

Finally, we would like to comment on the correlations between the implicit IAT measure and explicit measures of 
environmental attitudes. The issue of correspondence between implicit and explicit measures has sparked considerable debate (Dovidio, Kawakami, \& Beach, 2001; Fazio \& Olson, 2002). A sizable number of studies have failed to find a significant positive relationship between IAT measures of attitudes and explicit measures; and when correlations are found, they tend to be quite low. However, our findings show a consistent pattern of correlations in the predicted direction. Across the studies reported in this manuscript, we found routinely that IAT-nature scores correlated with self-reported connections with nature (positively), biospheric environmental concerns (positively), and egoistic environmental concerns (negatively). Fazio and Olson suggested that the correspondence between implicit and explicit measures tends to be higher for "mundane, socially noncontroversial objects” (p. 304). Our results are consistent with this interpretation: Environmental attitudes are less controversial than are racial prejudice or sexist attitudes.

Overall, our findings are consistent with recent work showing the importance of identity and self in understanding environmental attitudes (Clayton \& Opotow, 2003; Mayer \& Frantz, 2004; Schultz, 2001, 2002). At a broad level, the findings using the Implicit Association Test provide convergent evidence for an individual's connectedness with nature. However, our findings do not indicate that the IAT provides a superior measure over existing explicit measures (e.g., INS, biospheric environmental concerns, environ- mental identity, or Connectedness With Nature scale). Indeed, the findings for the IAT-nature scale tended to parallel those obtained using the INS explicit measure of connectedness (but not explicit measures of environmental concern). Despite our claim that connectedness with nature is a primitive belief, it does not appear that the IAT offers a magic tool with which to assess these latent beliefs. Rather, our results corroborate the existence of this construct, its usefulness in understanding environmental attitudes, its discriminant validity from explicit measures of environmental concern, and a new tool with which to test hypotheses derived from the emerging theories about connectedness with nature.

We have proposed in this article that the extent to which 
an individual associates himself or herself with the natural environment is a primitive belief (Dunlap et al., 2000) and that it forms the basis for a person's understanding of his or her place in both the natural and the social world. Despite the primitive origins of these beliefs, however, our data suggest that certain experiences may be associated with changes in implicit connections with nature. While the data reported in this manuscript cannot definitively address the issue of causation, the results do show that people with a greater implicit connection with nature spend more time in natural settings, such as the beach or a hiking trail (but not a golf course).

Clearly, many questions about the causal pathways involved in this relationship remain for future research. However, this set of studies has shown the usefulness and versatility of the Implicit Association Test. In the present studies, a Palm ${ }^{\circledR}$ version of the IAT allowed us to examine questions about the implicit connections between humans and nature in a variety of field settings. Given recent societal trends toward urbanization, and the resulting reduction in individual experiences in nature, these findings lead to some provocative applied research questions for social psychologists. 


\section{References}

Ajzen, I., \& Driver, B. L. (2001). Application of the theory of planned behavior to leisure choice. Journal of Leisure Research, 24, 207-224.

Aron, A., Aron, E. N., \& Smollan, D. (1992). Inclusion of Other in the Self scale and the structure of interpersonal closeness. Journal of Personality and Social Psychology, 63, 596-612. Aron, A., Aron, E. N., Tudor, M., \& Nelson, G. (1991). Close relationship as including other in the self. Journal of Personality and Social Psychology, 60, 241-253.

Bateson, G. (1972). Steps to an ecology of mind. Chicago, IL: University of Chicago Press.

Baumeister, R. (1998). The self. In D. Gilbert, S. Fiske, \& G.

Lindzey (Eds.), Handbook of social psychology (4th eds., Vol. 2, pp. 680-740). New York: McGraw-Hill.

Baumeister, R., \& Twenge, J. (2003). The social self. In T.

Millon \& M. Lerner (Eds.), Handbook of psychology:

Personality and social psychology (Vol. 5, pp. 327-352).

New York: Wiley.

Bem, D. J. (1970). Beliefs, attitudes, and human affairs. Belmont, CA: Brooks- Cole.

Blanton, H., \& Jaccard, J. (2006). Tests of multiplicative models in psychol- ogy: A case study using the unified theory of implicit attitudes, stereo- types, self-esteem, and selfconcept. Psychological Review, 113, 155-165. Bradley, M. M., \& Lang, P. J. (1999). Affective norms for English words (ANEW). Gainesville, FL: NIMH Center for the Study of Emotion and

Attention, University of Florida.

Brown, J. (1998). The self. Boston: McGraw-Hill.

Bruni, C., Schultz, P. W., \& Bowlin, J. (2006, January).

Catching implicit attitudes: An implicit association game.

Poster presented at the annual meeting of the Society for

Personality and Social Psychology, Palm Springs, CA.

Cai, H., Sriram, N., Greenwald, A., \& McFarland, S. (2004).

The Implicit Association Test's D measure can minimize cognitive skill confound. Social Cognition, 22, 673-684. Chawla, L. (1998). Significant life experiences revisited: A 
review of research on sources of environmental sensitivity. Journal of Environmental Education, 29, 11-21.

Clayton, S. (2003). Environmental identity: A conceptual and an operational definition. In S. Clayton \& S. Opotow (Eds.), Identity and the natural environment (pp. 45-65).

Cambridge, MA: MIT Press.

Clayton, S., \& Opotow, S. (2003). Identity and the natural environment.

Cambridge, MA: MIT Press.

Cunningham, W. A., Preacher, K. J., \& Banaji, M. R. (2001).

Implicit atti- tude measures: Consistency, stability, and convergent validity. Psycho- logical Science, 12, 163-170.

Dabbs, J., Bassett, J., \& Dyomina, N. (2003). The Palm ${ }^{\circledR}$ IAT:

A portable version of the Implicit Association Test.

Behavior, Research Methods, Instruments, and Computers, 35, 90-95.

Dovidio, J. F., Kawakami, K., \& Beach, K. R. (2001). Implicit and explicit attitudes: Examination of the relationship between measures of intergroup bias. In R. Brown \& S. L. Gaertner (Eds.), Blackwell handbook of social psychology: Intergroup processes (pp. 175-197). Malden, MA:

Blackwell. Dunlap, R. E., Gallup, G. H., \& Gallup, A. M. (1995). Of global concern: Results of the Health of the Planet Survey. Environment, 35, 11-15, 33-39.

Dunlap, R. E., \& Saad, L. (2001). Only one in four Americans are anxious about the environment: Most favor moderate approach to environmental protection. Gallup Poll Monthly, 427, 6-16.

Dunlap, R., Van Liere, K., Mertig, A., \& Jones, R. E. (2000).

Measuring endorsement of the new ecological paradigm: A revised NEP scale. Journal of Social Issues, 56, 425-442.

Dutcher, D. (2000). Landowner perceptions of protecting and establishing riparian forests in central Pennsylvania. Unpublished doctoral disserta- tion, Pennsylvania State University, School of Forest Resources.

Elder, J., \& Wong, H. (1994). Family of earth and sky: Indigenous tales of nature from around the world. Boston: Beacon Press.

Fazio, R., \& Olson, M. (2002). Implicit measures in social cognition research: Their meaning and use. Annual Review of 
Psychology, 54, 297-327.

Greenwald, A. G., Banaji, M. R., Rudman, L. A., Farnham, S. D., Nosek,

B. A., \& Mellot, D. S. (2002). A unified theory of implicit attitudes, stereotypes, self-esteem, and self-concept.

Psychological Review, 109, 3-25. Greenwald, A. G., McGhee, D. E., \& Schwartz, J. L. K. (1998). Measuring individual differences in implicit cognition. Journal of Personality and Social Psychology, 74, 1464-1480.

Greenwald, A. G., Nosek, B., \& Banaji, M. (2003).

Understanding and using the Implicit Association Test: I. An improved scoring algorithm. Journal of Personality and Social Psychology, 85, 197-216.

Higgins, E. T. (1996). The "self-digest": Self knowledge serving self- regulatory functions. Journal of Personality and Social Psychology, 71, 1062-1083.

Hoffman, C. (2000). The hoop and the tree. San Francisco: Council Oak.

Kahn, P. (1999). The human relationship with nature:

Development and culture. Cambridge, MA: MIT Press.

Kaiser, F., Hübner, G., \& Bogner, F. (2005). Contrasting the theory of planned behavior with the value-belief-norm model in explaining conservation behaviors. Journal of Applied Social Psychology, 35, 2150- 2170.

Karpinski, A., \& Hilton, J. L. (2001). Attitudes and the Implicit

Association Test. Journal of Personality and Social

Psychology, 81, 774-788.

Kellert, S. (1996). The value of life. Washington, DC: Island Press.

Kidner, D. (2001). Nature and psyche: Radical environmentalism and the politics of subjectivity. New York: State University of New York Press.

Kline, B. (2000). First along the river: A brief history of the U.S. environmental movement ( $2^{\text {nd }}$ ed.). San Francisco: Acada Books.

Kunda, Z. (2001). Social cognition: Making sense of people. Cambridge, MA: MIT Press.

Leopold, A. (1949). A Sand County almanac and sketches here and there. New York: Oxford University Press. 
Louv, R. (2005). Last child in the woods. Chapel Hill, NC: Algonquin Books. Markus, H. (1977). Self-schemata and processing information about the self.

Journal of Personality and Social Psychology, 35, 63-78. Mayer, F. S., \& Frantz, M. (2004). The Connectedness to Nature scale: A measure of individuals' feeling in community with nature. Journal of Environmental Psychology, 24, 503-515.

MRC Psycholinguistic Database: Machine Usable Dictionary.

Version 2.00 (1987). Retrieved March 15, 2003, from http://www.psy.uwa.edu.au/mrcdatabase/uwa_mrc.htm Nabhan, G. P., \& Trimble, S. (1994). The geography of childhood: Why children need wild places. Boston: Beacon.

Neisser, U. (1997). The roots of self-knowledge: Perceiving self, it, and thou. In J. Snodgrass \& R. Thompson (Eds.), The self across psychology (pp. 18-33). New York: New York Academy of Sciences.

Öhman, A. (1979). Fear relevance, autonomic conditioning, and phobias: A laboratory model. In P. O. Sjödén, S. Bates, \& W. S. Dockens (Eds.), Trends in behavior therapy (pp. 107134). New York: Academic Press.

Öhman, A., \& Mineka, S. (2001). Fears, phobias, and preparedness: Toward an evolved module of fear and fear learning. Psychological Review, 108, 483-522.

Oskamp, S., \& Schultz, P. W. (2005). Attitudes and opinions (3rd ed.).

Mahwah, NJ: Lawrence Erlbaum.

Ponting, C. (1991). A green history of the world: The environmental collapse of great civilizations. New York: Penguin Books.

Rokeach, M. (1968). Beliefs, attitudes, and values: A theory of organization and change. San Francisco: Jossey-Bass. Schultz, P. W. (2000). Empathizing with nature: The effects of perspective taking on concern for environmental issues. Journal of Social Issues, 56, 391-406.

Schultz, P. W. (2001). The structure of environmental concern:

Concern for self, other people, and the biosphere. Journal of Environmental Psychol- ogy, 21, 1-13.

Schultz, P. W. (2002). Inclusion with nature: Understanding 
human-nature interactions. In P. Schmuck \& P. W. Schultz (Eds.), The psychology of sustainable development (pp. 6178). New York: Kluwer.

Schultz, P. W., Shriver, C., Tabanico, J., \& Khazian, A. (2004). Implicit connections with nature. Journal of Environmental Psychology, 24, 31-42.

Searles, H. (1960). The nonhuman environment: In normal development and schizophrenia. New York: International Universities Press.

Stern, P. C. (2000). Toward a coherent theory of environmentally significant behavior. Journal of Social Issues, 56, 407-424.

Thomashow, M. (1995). Ecological identity: Becoming a reflective environ- mentalist. Cambridge, MA: MIT Press. Thoreau, H. D. (1987). Walden. Philadelphia: Running Press. (Original work published 1854).

Weigert, A. J. (1997). Self, interaction, and natural environment: Refocusing our eyesight. New York: SUNY Press.

Wilson, E. O. (1984). Biophilia. Cambridge, MA: Harvard University Press. Wilson, E. O. (1993). Biophilia and the conservation ethic. In S. R. Kellert \&

E. O. Wilson (Eds.), The biophilia hypothesis (pp. 31-41). Washington, DC: Island Press. 


\section{Appendix ${ }^{9}$}

Materials for the Palm ${ }^{\circledR}$ Pilot Implicit Association Test (IAT)

Following is the text for the GSU.stimulus file:

NATURE,BUILT,NATURE,BUILT, animals, birds,plants, buildin g,car, city, whales,trees, water,street,factory,computer

ME,NOT-ME,ME,NOT-

ME,I,me,mine,it,other,their,self,myself,my,them, they,theirs

BUILT,NATURE,ME,NOT-

ME,street,factory,computer, whales,trees,

water,self,myself,my,them,they,theirs

BUILT,NATURE,ME,NOT-

ME,building,car,city,animals,birds,plants,

I,me,mine,it,them,they

BUILT,NATURE,BUILT,NATURE,building,car,city, whales,tre es,water, street,factory,computer,animals,birds,plants

NATURE,BUILT,ME,NOT-

ME, whales,trees, water,street,factory,

computer,self,myself,my,them,they,theirs

NATURE,BUILT,ME,NOT-

ME,animals,birds,plants,building,car,city,I,

me,mine,it,them,they

${ }^{9}$ The application, instruction, and source code for the Palm ${ }^{\circledR}$ Pilot IAT procedure are available at www.singletap.com/research. Researchers who wish to obtain our Excel scoring converter for the Palm ${ }^{\circledR}$ datafiles should contact the first author. 